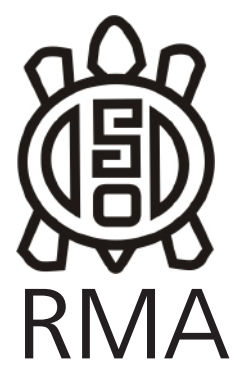

Dossier

DOSSIER:

\title{
Metodologías y Técnicas Aplicadas en Zooarqueología: Avances y Perspectivas
}

\author{
Silvana V. Urquiza* y Gabriela Srur** \\ * ISES-CONICET. Facultad de Ciencias Naturales e Instituto Miguel Lillo, \\ Universidad Nacional de Tucumán. \\ ** Museo de Antropología, IDACOR, CONICET. Facultad de Filosofía y \\ Humanidades, Universidad Nacional de Córdoba. \\ E-mail: silvanaurquiza@yahoo.com; gabrielasrur@hotmail.com
}

El presente dossier de la Revista del Museo de Antropología (RMA) reúne una selección de trabajos presentados en el Simposio Metodologías y Técnicas Aplicadas en Zooarqueología: Avances y Perspectivas. Este simposio ha sido desarrollado en el marco del I/ Congreso Nacional de Zooarqueología Argentina (II CNZA), en Olavarría (Provincia de Buenos Aires) entre el 9 y 13 de Mayo del 2011.

En los últimos años los modos de investigar el material faunístico se han visto enriquecidos por innovaciones metodológicas y técnicas, que permitieron abordar de manera más eficaz problemas clásicos y recientes de la arqueología. Las cinco contribuciones compendiadas tratan las regiones del Noroeste y la Patagonia argentina, reflejando el crecimiento y consolidación que han tenido las investigaciones en zooarqueología.

El primer trabajo, de Fernando Santiago y Martín Vázquez, nos propone un acercamiento al consumo faunístico para una región y una cronología específica. Mediante el empleo de índices de abundancia económica y de Sistemas de Información Geográfica (SIG) obtienen valores promediados sobre el aprovechamiento animal. Lo interesante de este aporte es que se logra una sistematización de los datos económicos a escala suprarregional, abarcando desde el Holoceno temprano hasta el contacto con la sociedad occidental en el archipiélago de Tierra del Fuego, demostrando la operatividad de esta metodología y su aplicabilidad a nivel intersitios.

María del Carmen Reigadas estudia la estructura física celular de las fibras animales, aplicando microscopio biológico y electrónico de transmisión (MET) a una selección de muestras de dos sitios aleros de cazadoresrecolectores tempranos de la Puna austral (Antofagasta de la Sierra, Argentina). El enfoque novedoso se vincula al análisis de la corteza de las fibras, dato que hasta el momento era despreciado. De esta manera, establece nuevos indicadores interespecíficos como herramientas adicionales en las determinaciones taxonómicas. Lo que resulta significativo, sobre todo, en contextos con preservación ósea diferencial y sobre todo en la identificación de camélidos silvestres y domésticos.

Guillermo Ortiz y Silvana Urquiza desarrollan un estudio integrado, analizando vertebrados e invertebrados de un sitio Tardío-Inca de la Puna austral (Antofagasta de la Sierra, Argentina). Paralelamente, mediante métodos físico-químicos examinan el contexto sedimentario que contuvo al conjunto arqueofaunístico. Integrando metodologías geo-bioquímicas y entomoarqueológicas, disciplinas incipientes en la arqueología argentina, se logran resolver cuestiones arqueológicas y tafonómicas.

Mariana Dantas presenta una original contribución para la identificación interespecífica, conjugando los estudios osetometricos y los isótopos estables sobre material óseo de Camelidae. De esta manera, establece la presencia de dos grupos de camélidos domésticos, de grande y pequeño porte, en Valle de Ambato (Catamarca) entre los siglos VI y X d.C. Resultando trascendental la estrategia agropastoril de alimentación selectiva de Lama glama con plantas C4, sobre todo para noroeste argentino y de la región andina.

Por último, en el trabajo de Gabriela Srur y coautores se propone una metodología físico-química para la caracterización del registro óseo faunístico mediante dos métodos: uno destructivo - Adición Estándar-y otro no destructivo -Reemplazo de la Matriz Ósea-. Ambos han sido probados ponderando las concentraciones de estroncio en partes esqueletales de Lama glama arqueológicas. Si bien es una metodología nueva, es a la vez prometedora en la resolución de problemas arqueológicos vinculados a la dieta y movilidad.

Todos los trabajos presentados incorporan criterios que fortalecen las metodologías y técnicas de la especialidad, generando respuestas a cuestiones recurrentes y abriendo nuevos interrogantes. La osteometría, química, sedimentología, los SIG y la tafonomía han adquirido gran relevancia, como resultado de los avances tecnológicos de las últimas décadas. Esto permite el abordaje de problemas a diferentes escalas de análisis, micro y macroscópica. Conocer en detalle estas nuevas propuestas, puede ayudarnos a plantear nuevas hipótesis, y vislumbrar nuevas respuestas. 
Agradecemos a todos los autores y evaluadores que participaron en este dossier. Y especialmente a Andrés Izeta, quien además de co-coordinar el simposio, brindó un espacio apropiado para estas contribuciones en la RMA.

San Miguel de Tucumán, Octubre de 2012. 